\title{
Reducing false positive prediction of miRNA target genes with RNA sequencing: Hype or hope
}

\author{
Vinod Kumar* \\ Department of Medicine, Division of Hematology-Oncology, UPMC Hillman Cancer Center, University of Pittsburgh, Pittsburgh, PA 15213, USA
}

The microRNAs (miRNAs) regulate many biological processes and their altered expression is reported in many diseases including cancer [1-5], diabetes [6-8], and liver fibrosis [9-11]. They are never translated but manipulate gene expression by base-pairing with the 3 ' untranslated region (UTR) of their target mRNAs. Firstly, they were discovered as a short RNA produced by the lin-4 gene in Caenorhabditis elegans which represses the lin-14 mRNA. Initially, it was thought that they are unique only to nematodes but now it is well demonstrated that they are abundant in the diverse animal kingdom. It is also well established that they are involved in every cellular process including cell differentiation, proliferation, apoptosis, metastasis, and chemoresistance. More than $60 \%$ of protein-coding genes in the human harbor's miRNA target site [12]. In cancer, they can be oncomirs (oncogenes), tumor suppressors, prognostic markers, or therapeutic target. Since the expression pattern of miRNAs are highly specific, and functionally they regulate at the epigenetic level in genome, they are attractive biomarkers in medical research. These relatively new class of gene regulators has opened a new direction for drug discovery. Interest in miRNA-based therapy is now growing rapidly and literature is getting enriched with novel miRNAs and their target genes. Even though, miRNA-based therapy in the clinic is still far from the sight and many obstacles related to the specificity, stability, and delivery need to be addressed. Nonetheless, a clinical trial for some miRNA has already been initiated based on exciting data in non-human primates $[13,14]$. Since the expression profile of miRNAs is disease and tissue- specific, they can be more informative than the mRNA profile. The first disease specific expression (loss of) of miRNA was exploited in chronic lymphocytic leukemia [15]. The tissue specific miRNA expression was also reported in many cases [16-19]. The superior stability of these short miRNAs than mRNA and longer RNAs make them a good and reliable diagnostic target.

Despite tremendous preclinical studies, only a few miRNA have moved to clinical development. Identifying the best target for miRNA for each disease type, delivery vehicle, stability, tissue specificity, toxicity, and off-target effect could be the main reason for their slow clinical development [20-22]. The challenge in identifying the suitable target for miRNA is due to the fact that miRNA expression pattern is heterogeneous even within the same disease and is affected by local factors like hypoxia and inflammation. Nevertheless, their small size and association with other proteins prevents their degradation by RNAses and makes them a good molecule for precision medicine. However, many questions regarding the regulation of miRNA function remain unanswered. There is currently a need to develop a tool that can identify the right target mRNA for particular miRNA which can be used in biomarker discovery and novel therapies for many aggressive diseases including cancer. A single miRNA can target many mRNA and an mRNA can be targeted by many miRNAs. Furthermore, a disease can have several altered signaling pathways and a single pathway may be altered in many diseases [23-26]. This "one-to-many" relationship between mRNA and miRNA results in a robust regulatory network, which controls the cell proliferation and disease process.

Experimentally, it is difficult to determine the relationship between miRNA and their target mRNA. Luciferase assay-based expression of mRNA and pulsed stable isotope labeling amino acid in culture are routinely used methods to determine their relationship. These methods eventually measure the protein derived from mRNA regulated by miRNA. Since protein expression is controlled by several other factors also, these are not the perfect methods. The more frequent method used to determine the miRNA target is complementarity in seed sequence. Various online databases such as miRBase, HMDDv2.0, and DIANATarBase are being used to predict the target gene for miRNA but the probability of false prediction is high. Most of these databases use the prediction algorithms which is sequence-specific not the disease/case specific thus can't avoid the false positive prediction. Furthermore, these online databases also rely on thermodynamic stability, evolutionary conservation, and sequence pairing of miRNA with their target mRNA but still, false interpretation remains a problem. To conquer these limitations a gene expression-based database for miRNA target prediction is needed. The gene expression-based database may improve the miRNA target prediction by mapping the inverse correlation between downregulated genes and overexpressed miRNA within the same disease type or vice versa. RNA sequencing (RNA seq) is a revolutionary tool which computes the transcript level with high accuracy and sensitivity compared to any other methods like qPCR and micro array [27]. The capacity to cover unlimited genome size, ability to identify splice variants, rapidly decreasing the cost allowed us to use RNA seq for clinical purpose, and generation of large-scale robust datasets for miRNA-mRNA interactions. The identification of miRNA targets is difficult to examine experimentally. Current methods have severe limitations like weak expression, tissue specificity, and miRNA stabilization. Combining the integrated expression RNA-seq data from several different tumor types with epigenetic modulators like gene methylation and copy number alternation may reduce the false positive miRNA targets. In cancer, there are many factors which contributes to the disease prognosis and survival like patient age, gender, nature of the tumor (aggressive vs non aggressive), drug resistance, metastasis, etc. Therefore, a single factor i.e. sequence complementarity of miRNA

${ }^{\star}$ Correspondence to: Vinod Kumar, Department of Medicine, Division of Hematology-Oncology, University of Pittsburgh, Hillman Cancer Center Research Pavilion, Lab: 2.7; 5117 Centre Avenue Pittsburgh, PA 15213-1863, USA, E-mail: kumarv3@upmc.edu

Received: July 15, 2020; Accepted: July 24, 2020; Published: July 27, 2020 
to mRNA should not be used to predict the appropriate miRNA target responsible for survival. Identification of miRNA target by RNA-seq data from different tumor types within cancer related pathways may increase the chance of miRNA-based therapeutics [28]. This approach may reduce the off-target effect/side effect and false-positive predictions. Unlike conventional drug therapies, miRNA targeted drugs have high regard it can modulate multiple pathways and biological processes. The ability to regulate thousands of genes may compensate for its efficacy and unexpected side effects. Therefore, downstream miRNA genes should be explored [29]. The miRNA-mRNA network-based approach by using RNA seq has the potential to target protein structure information and drug design in various diseases. This approach of developing miRNA-based therapeutics may create a paradigm in the pharmaceutical industry, therefore prediction of miRNA target by RNA seq is definitely a hope.

\section{References}

1. Lin S, Gregory RI (2015) MicroRNA biogenesis pathways in cancer. Nat Rev Cancer 15: 321-333.

2. Kumar V, Kumar V, Chaudhary AK, Coulter DW, McGuire T, et al. (2018) Impact of miRNA-mRNA Profiling and Their Correlation on Medulloblastoma Tumorigenesis. Mol Ther Nucleic Acids 12: 490-503. [Crossref]

3. Melo SA, Moutinho C, Ropero S, Calin GA, Rossi S, et al. (2010) A genetic defect in exportin-5 traps precursor microRNAs in the nucleus of cancer cells. Cancer Cell 18: 303-315.

4. Kumar V, Kumar V, McGuire T, Coulter DW, Sharp JG, et al. (2017) Challenges and Recent Advances in Medulloblastoma Therapy. Trends Pharmacol Sci 38: 1061-1084.

5. Heravi-Moussavi A, Anglesio MS, Cheng SW, et al. (2012) Recurrent somatic DICER1 mutations in nonepithelial ovarian cancers. $N$ Engl J Med 366: 234-242.

6. Poy MN, Eliasson L, Krutzfeldt J, Kuwajima S, Ma X, et al. (2004) A pancreatic isletspecific microRNA regulates insulin secretion. Nature 432: 226-230. [Crossref]

7. Poy MN, Hausser J, Trajkovski M, Braun M, Collins S, et al. (2009) miR-375 maintains normal pancreatic alpha- and beta-cell mass. Proc Natl Acad Sci USA 106: 5813-5818.

8. Hennessy E, Clynes M, Jeppesen PB, O'Driscoll L (2010) Identification of microRNAs with a role in glucose stimulated insulin secretion by expression profiling of MIN6 cells. Biochem Biophys Res Commun 396: 457-462.

9. Roderburg C, Urban GW, Bettermann K, Vucur M, Zimmermann H, et al. (2011) Micro-RNA profiling reveals a role for miR-29 in human and murine liver fibrosis. Hepatology 53: 209-218.

10. Kumar V, Kumar V, Luo J, Mahato RI (2018) Therapeutic Potential of OMe-PS-miR29b1 for Treating Liver Fibrosis. Mol Ther 26: 2798-2811.

11. Schueller F, Roy S, Loosen SH, Alder J, Koppe C, et al. (2017) miR-223 represents a biomarker in acute and chronic liver injury. Clin Sci (Lon) 131: 1971-1987.
12. Gebert L, MacRae IJ (2019) Regulation of microRNA function in animals. Nat Rev Mol Cell 20: 21-37. [Crossref]

13. Reid G, Kao SC, Pavlakis N, Brahmbhatt H, MacDiarmid J, et al. (2016) Clinical development of TargomiRs a miRNA mimic-based treatment for patients with recurrent thoracic cancer. Epigenomics 8: 1079-1085.

14. Van Zandwijk N, Pavlakis N, Kao SC, Linton A, Boyer MJ, et al. (2017) Safety and activity of microRNA-loaded minicells in patients with recurrent malignant pleural mesothelioma: a first-in-man phase 1 open-label dose-escalation study. Lancet Oncol 18: 1386-1396.

15. Calin GA, Dumitru CD, Shimizu M, Bichi R, Zupo S, et al. (2002) Frequent deletions and down-regulation of micro- RNA genes miR15 and miR16 at 13q14 in chronic lymphocytic leukemia. Proc Natl Acad Sci USA 99: 15524-15529.

16. Lu J, Getz G, Miska EA, Alvarez-Saavedra E, Lamb J, et al. (2005) MicroRNA expression profiles classify human cancers. Nature 435: 834-838. [Crossref]

17. Benjamin H, Lebanony D, Rosenwald S, Cohen L, Gibori H, et al. (2010) A diagnostic assay based on microRNA expression accurately identifies malignant pleural mesothelioma. J Mol Diagn 12: 771-779.

18. Rosenwald S, Gilad S, Benjamin S, Lebanony D, Dromi N, et al. (2010) Validation of a microRNA-based qRT-PCR test for accurate identification of tumor tissue origin. Mod Pathol 23: 814-823.

19. Lee YS, Dutta A (2009) MicroRNAs in cancer. Annu Rev Pathol 4: 199-227.

20. Van Rooij E, Kauppinen S (2014) Development of microRNA therapeutics is coming of age. EMBO Mol Med 6: 851-864. [Crossref]

21. Cheng CJ, Slack FJ (2012) The duality of oncomiR addiction in the maintenance and treatment of cancer. Cancer J 18: 232-237.

22. Rupaimoole R, Han HD, Lopez-Berestein G, Sood AK (2011) MicroRNA therapeutics: principles expectations and challenges. Chin J Cancer 30: 368-370. [Crossref]

23. Kumar V, Chaudhary AK, Dong Y, Zhong HA, Mondal G, et al. (2017) Design Synthesis and Biological Evaluation of novel Hedgehog Inhibitors for treating Pancreatic Cancer Sci Rep 7: 1665 .

24. Rupaimoole R, Calin GA, Lopez-Berestein G, Sood AK (2016) miRNA Deregulation in Cancer Cells and the Tumor Microenvironment. Cancer Discov 6: 235-246.

25. Kumar V, Dong Y, Kumar V, Almawash S, Mahato RI, et al. (2019) The use of micelles to deliver potential hedgehog pathway inhibitor for the treatment of liver fibrosis. Theranostics 9: 7537-7555. [Crossref]

26. Li Z, Rana TM (2014) Therapeutic targeting of microRNAs: current status and future challenges. Nat Rev Drug Discov 13: 622-638.

27. Wang Z, Gerstein M, Snyder M (2009) RNA-Seq: a revolutionary tool for transcriptomics. Nat Rev Genet 10: 57-63.

28. Andrés-León E, Cases I, Alonso S, Rojas AM (2017) Novel miRNA-mRNA interactions conserved in essential cancer pathways. Sci Rep 7: 46101

29. Schmidt MF (2014) Drug target miRNAs: chances and challenges. Trends Biotechnol 32: 578-585. [Crossref]

Copyright: (C2020 Kumar V. This is an open-access article distributed under the terms of the Creative Commons Attribution License, which permits unrestricted use, distribution, and reproduction in any medium, provided the original author and source are credited. 